\title{
Trastorno de la marcha en una niña de dos años: importancia de las revisiones del programa de salud infantil
}

\author{
S. Piris Borregas ${ }^{a}$, MR.Acuña Aller \\ ${ }^{\circ}$ MIR-Pediatría. Hospital Universitario 12 de Octubre. Madrid. España. \\ bPediatra. CS Martín de Vargas. Madrid. España.
}

Fecha de publicación en Internet: 14 de diciembre de 2011

\section{Resumen}

La ataxia es un motivo de consulta relativamente frecuente en Atención Primaria. La mayor parte de las veces se presenta de forma aguda como consecuencia de causas banales. Sin embargo, en ocasiones como en el caso presente, es necesaria una exploración detallada y atenta en las revisiones sistemáticas del programa de salud infantil para ponerla de manifiesto, siendo generalmente en estos casos parte de un cuadro clínico más grave y larvado cuya detección y manejo precoz son los factores que más influyen en su mejor pronóstico.

Se ofrece a continuación un caso clínico que pone de relieve la importancia de las revisiones sistemáticas y plantea el diagnóstico diferencial de la ataxia infantil.

Palabras clave: Hidrocefalia. Ataxia. Dandy-Walker.

Walking disturbance in a two years old child: the importance of the well child program

Abstract

Ataxia is a relatively common reason for consultation in primary care. Most often it presents acutely as a result of banal causes. However, sometimes, we need a detailed and careful examination in the systematic reviews of healthy children to observe it, being in these cases part of a more severe clinical disease. An early detection and management are the factors that powerfully influence the prognosis.

We report a case that highlights the importance of systematic reviews and differential diagnosis of ataxia.

Key words: Ataxia. Hydrocephalus. Dandy-Walker.

\section{Introducción}

La incoordinación durante la marcha, La identificación semiológica del daño tal y como se define la ataxia, puede te- neurológico y la frecuencia de la etiolo-

Salvador Piris Borregas, dockbps@hotmail.com

Los autores declaran no presentar conflictos de intereses en relación con la preparación y publicación de este artículo. 
gía infantil suponen sendos factores importante para la identificación del origen y su manejo precoz.

De esta manera, según la clínica del paciente, se podría identificar una ataxia cerebelosa, en cuyo caso asociaría dismetría, disdiadococinesia y temblor intencional; una ataxia sensorial por alteración de los cordones posteriores (menos frecuente en la edad pediátrica), o una alteración de las conexiones vestibulares ${ }^{1,2}$.

Es sumamente importante el conocimiento y el seguimiento de los hitos del desarrollo psicomotor durante las revisiones sistemáticas infantiles para identificar alteraciones neurológicas lo más precozmente posible, tal y como se describe en el caso que se detalla a continuación.

\section{Caso clínico}

En una revisión de una niña de dos años de edad, su pediatra de cabecera descubre una marcha torpe: sabe ponerse de pie sin ayuda, no sabe correr, chuta el balón con ambos pies y sube y baja escaleras agarrada de las manos. No se describen alteraciones neurológicas familiares de interés.

\section{Antecedentes personales}

Nacida tras una gestación a término mediante cesárea por presentación podálica. Peso al nacer, $2780 \mathrm{~g}$; test de Apgar, 8/9; reanimación tipo II. Pruebas endocrinometabólicas normales. Vacunación al día. Desarrollo psicomotor: sonrisa social a los dos meses, sostén cefálico a los tres meses, sedestación a los siete meses, gateo a los ocho meses, marcha sin apoyo a los 17 meses, motricidad fina normal. Bisílabos no referenciales a los ocho meses, bisílabos referenciales a los 12 meses.

\section{Exploración física}

Talla, $92 \mathrm{~cm}$ (percentil $\left.97\left[\mathrm{P}_{97}\right]\right)$; peso, $11,8 \mathrm{~kg}\left(\mathrm{P}_{25-50}\right)$; perímetro craneal. 53,3 $\mathrm{cm}\left(\mathrm{P}_{97}\right)$. Buen estado general. Bien nutrida. Sin dismorfias ni discromías. Cráneo normoconfigurado. Auscultación cardiopulmonar normal. Abdomen depresible y sin organomegalias. Genitales externos femeninos y normales. Exploración neurológica: hábito longilíneo con buena alineación del raquis y de las extremidades; pares craneales normales; tono activo normal; leve hipotonía pasiva con signo de la bufanda que sobrepasa la línea media y dedo al antebrazo; en los miembros inferiores, el ángulo poplíteo supera los $90^{\circ}$ y hace abducción completa de caderas; reflejos osteotendinosos presentes y simétricos; llama la atención la marcha ligeramente oscilante, no claudicante; no dismetría, signo de Romberg negativo; ausencia de disdiadococinesia; pinza digital normal; maniobra de 
Gowers negativa; sin hipertrofia gemelar.

\section{Evolución posterior}

El paciente es remitido a la consulta de Neurología con control clínico cada tres meses. Se solicitó un hemograma, una bioquímica general, pruebas tiroideas y creatinfosfocinasa, con resultados normales. Durante los siguientes seis meses la niña desarrolló una macrocefalia de +3,6 desviaciones estándar (DS) y un discreto temblor intencional, sin mejoría de la torpeza motora en la deambulación, por lo que se solicitó un resonancia magnética cerebral, en la que se descubrió una llamativa dilatación de los cuatro ventrículos cerebrales con quiste retrocerebeloso sin evidencia de otras malformaciones asociadas, sugerente todo ello de una alteración de la fosa posterior en el contexto del complejo de Dandy-Walker.

Se recomendó, por parte de Neurología, fisioterapia mediante el método Bobath, con la que se ha detenido, por el momento, el deterioro neurológico.

\section{Discusión}

La instauración brusca de una incoordinación de la marcha debe sugerir la presencia de una intoxicación (especialmente por alcohol, benzodiazepinas y antitusivos) o una cerebelitis postinfecciosa aguda. Esta última es la causa más frecuente de la ataxia en la edad infantil, ocurriendo entre una y dos semanas después de una infección generalmente viral. Suele asociar otros síntomas como cefalea, alteraciones del comportamiento y signos de incoordinación motora fina. Las pruebas de neuroimagen son normales y la clínica suele ceder en unas 3-5 semanas con pronóstico excelente por lo general ${ }^{3,4}$.

Las formas más larvadas de la ataxia plantean un diagnóstico diferencial más extenso, sabiendo que a veces pueden pasar desapercibidas hasta manifestarse de forma más o menos aguda. Entre dichas causas cabe destacar las siguientes:

- Infecciones del sistema nervioso central (SNC): la presencia de fiebre y la alteración del nivel de conciencia marcan su principal sospecha. El líquido cefalorraquídeo (LCR), extraído mediante punción lumbar, suele estar alterado ${ }^{5,6}$.

- Tumores de fosa posterior: la presencia de hidrocefalia por el sangrado o el efecto masa, y/o la hipertensión intracraneal suelen desencadenar la focalidad neurológica 5 .

- Traumatismo craneoencefálico: aunque la recuperación es excelente, la clínica suele ser larvada y prolongarse durante meses ${ }^{5,6}$. 
- Malformaciones del SNC: en la edad pediátrica suelen afectar fundamentalmente a la fosa posterior, siendo necesarias para su diagnóstico las pruebas de imagen (resonancia magnética). En este apartado cabe destacar por su frecuencia el complejo de Dandy-Walker, que consiste en un quiste retrocerebeloso que se comunica con el cuarto ventrículo dificultando el drenaje normal del LCR y provocando así una hidrocefalia no comunicante que se manifiesta como una ataxia con macrocefalia y se suele acompañar de otros síntomas cerebelosos tales como la dismetría o el temblor intencional. Se diagnostica mediante pruebas de imagen y el tratamiento tan solo es quirúrgico en casos avanzados ${ }^{5,6}$.

- Otras causas menos frecuentes son la enfermedad de Fisher Miller, una variante de síndrome de GuillainBarré, las reacciones psicógenas, algunas enfermedades metabólicas o la patología cerebrovascular.

Sean cuales sean la causa y el nivel de la disfunción neurológica, lo más importante es detectar cuanto antes el estancamiento del desarrollo psicomotor, para lo cual es necesario realizar de forma atenta y exhaustiva una adecuada valoración neurológica del niño en sus revisiones sistemáticas.

\section{Bibliografía}

1. Connolly AM, Dodson WE, Prensky AL, Rust RS. Course and outcome of acute cerebellar ataxia. Ann Neurol. 1994;35:673-9.

2. Fenichel GM. Ataxia. En: Fenichel GM (ed.). Clinical Pediatric Neurology: a signs and symptoms approach, 3rd edition. Philadelphia: W. B. Saunders Company; 1997. p. 230-52.

3. Ryan MM, Engle EC. Acute ataxia in childhood. J Child Neurol. 2003;18:309-16.

4. Martínez-González MJ, Martínez-Gonzaléz S, García-Ribes A, Mintegi-Raso S, Benito-Fernán- dez J, Prats-Viñas JM. Ataxia de aparición aguda en la infancia: etiología, tratamiento y seguimiento. Rev Neurol. 2006;42:321-4.

5. Swaimann KF. Acute cerebellar ataxia. En Swaimann KF (ed.). Pediatric Neurology. Principles and Practice, 4th edition. St. Louis: MosbyYear Book, Inc.; 2006. p. 1296-7.

6. Kinsman SL, Johnston MV. Hidrocefalia. En: Kliegman RM, Behrman RE, Jenson HB, Stanton BJ. Nelson Tratado de Pediatría, 18. ${ }^{a}$ ed. Madrid: Elsevier; 2009. p. 2452-5. 